\title{
Submission to the will of God: Religion/Spirituality as a Cultural Resource of Indonesian Women Living with Cardiovascular Disease
}

\author{
Sutantri Sutantri ${ }^{1 *}$ \\ ${ }^{1}$ Department of Nursing, Faculty of Medicine and Health Sciences, Universitas Muhammadiyah Yogyakarta, Yogyakarta, \\ Indonesia
}

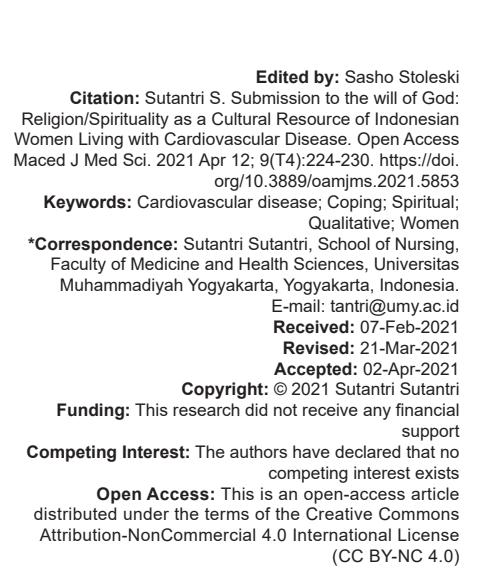

\section{Abstract}

BACKGROUND: Cardiovascular disease (CVD) is the number one killer of women. Suffering from illness causes a significant challenge for women's day-to-day lives. Understanding the women's experiences and descriptions of managing their illness, strategies are essential for minimizing CVDs negative consequences.

AIM: This study aims to investigate cultural adjustment to CVD among women in Indonesia.

METHODS: This study employed a qualitative research design with in-depth interviews. Twenty-six women who had an experience of the cardiac event participated in this study. A qualitative framework analysis was used to analyze the data.

RESULTS: Five themes were identified from data analysis. These themes were (1) making meaning of the situation, (2) feeling grateful amidst suffering, (3) submission to the will of God, (4) accepting fate, and (5) getting closer to God. CONCLUSION: Spiritual and religious beliefs played an enormous role in the participants' illness experience, irrespective of their religions. Nurses should incorporate a religious and spiritual approach to facilitate patients coping behaviors when providing care for the Indonesian population.

\section{Introduction}

Although in the past, cardiovascular disease (CVD) has been thought of as "a man's disease" [1], $C V D$ is currently reported to be the number one cause of mortality among women globally [2]. This longstanding male-centered belief has meant that women with CVD have been neglected around the world [3]. The data in Indonesia indicate that since the 1990s, CVD has occupied the top ranking as the leading cause of mortality and now constitutes $37 \%$ of the country's total deaths [4]. Data from the 2018 National Basic Health Survey also showed that the prevalence of CVD among women was greater than men [5].

To provide effective care for the people affected by $C V D$, it is essential to understand the factors that influence people's illness experiences from various sociocultural backgrounds [6]. Despite the increasing CVD research trends that focus on women in high-income countries, there still appears a dearth of research addressing this area in the Indonesian context. Thus, there is an urgency to explore women's experiences in Indonesia, particularly due to Indonesia's distinct womanhood concept. The combination of cultural norms, state ideology, and Islamic norms has shaped womanhood's social construction [7]. In Indonesia, women are generally perceived as "inferior to men" in both cultural, religious, and political contexts [8]. Indonesian women have to maintain and preserve harmony in the family in a situation where they are required to submit, keep quiet, and make sacrifices [9]. For this reason, women's decision to undertake intensive treatment may be affected by this condition. In addition, Indonesia is also recognized as the most significant Muslim majority country globally, with about $87 \%$ of the Muslim population. Therefore, this study aims to investigate cultural adjustment to CVD among women in Indonesia.

\section{Methods}

This study employed an exploratory qualitative research design using a semi-structured interview to explore women's cultural adjustment to CVD in Indonesia. This method sat within a social constructionist worldview, which considered that reality is socially constructed through prolonged social interactions and relationships [10]. A 
total of 26 women who attended the Phase II CR program in the National Cardiovascular Center, Harapan Kita Hospital, Jakarta, Indonesia, participated in this study. The participants' selection criteria were as follows: (1) Women aged 18 years old and over and (2) had the experience of a cardiac event. We used a semi-structured interview guide to collect the data from participants between June and September 2016. All the interviews were carried out at the outpatient clinic at a date and time chosen by the participants. The duration of the interview ranged between $15 \mathrm{~min}$ and $75 \mathrm{~min}$.

The data were analyzed using a framework analysis approach [11], [12]. The steps included familiarization, initial thematic framework development, indexing, charting, and abstraction and interpretation [13]. During the process of data analysis, NVivo version 11 was used.

To ensure the research rigor, we followed several strategies suggested by Lincoln and Guba [14], including credibility, transferability, dependability, and confirmability. To ensure this study's credibility, we maintained prolonged engagement with participants and implemented informal member checking. We provided a thick description of the study to enhance transferability, such as detailed descriptions of the participants, location, methods, and the theoretical assumption underpinning this study. The use of NVivo 11 to store and manage the data was also an effort to ensure this study's dependability and confirmability.

This study had been approved by the research ethics committee at the University of Edinburgh and the local hospital (No: LB.02.01/II/0859/2016). Before the interview, all the participants had signed the informed consent, and they were also assured that their participation was voluntary so they could withdraw from the study at any time without any consequences.

\section{Results}

Twenty-six women took part in this study. The characteristics of the participants interviewed are displayed in Table 1. In describing their cultural adjustment in managing the illness, five themes were identified.

\section{Making meaning of the situation: "It's a test from God!"}

Suffering from heart disease caused the women to be unable to carry out their usual tasks and roles both in the family and society. The inability to perform social roles caused a threat to women's sense of self. Therefore, to cope with this situation, the women developed religious/ spiritual coping strategies. By accepting their condition and attributing their limitations as a test from God, women were able to deal with hardships and miseries. It was proved by the statements as follows: "Don't be afraid, just pray," "God always hears our prayers," "I leave my fate to God," and "Just pray, I believe there is a miracle," which were prevalent in the participants' stories. These findings align with the previous studies that reported religion and spirituality were crucial factors in coping with CVD and its symptoms [15], [16].

Table 1: Participants characteristics

\begin{tabular}{llll}
\hline Age & Ethnicity & Marital status & Religion \\
\hline 44 & Sundanese & Married & Islam \\
41 & Sundanese & Married & Islam \\
66 & Batak & Widowed & Christian \\
62 & Betawi & Widowed & Islam \\
32 & Betawi & Divorced & Islam \\
44 & Javanese & Married & Islam \\
43 & Sundanese & Married & Islam \\
36 & Minahasan & Married & Christian \\
54 & Javanese & Widowed & Christian \\
44 & South Sumatra & Married & Islam \\
33 & Javanese & Married & Islam \\
61 & Minangkabau & Widowed & Islam \\
58 & West Nusa Tenggara & Widowed & Christian \\
53 & Javanese & Married & Islam \\
36 & East Nusa Tenggara & Married & Christian \\
42 & Batak & Married & Christian \\
36 & Sundanese & Married & Islam \\
30 & Javanese & Married & Islam \\
30 & Javanese & Married & Islam \\
36 & Javanese & Married & Islam \\
58 & Minangkabau & Married & Islam \\
46 & Banjarese & Married & Christian \\
55 & South Sumatra & Married & Islam \\
58 & Minangkabau & Married & Islam \\
55 & South Sumatra & Married & Islam \\
49 & Javanese & Married & Christian \\
\hline
\end{tabular}

\section{Feeling grateful amid suffering}

The analysis revealed that the participants still showed their gratitude to God even in the worst situations. The women tended to compare their situations with others who were worse off than themselves, which made them feel grateful amid their suffering. It is apparent that despite the hardships and miseries experienced by the women in this study, they did not attempt to question or blame anyone but accepted their suffering with gratitude. They were able to handle an uncertain future due to their faith. Showing gratitude under challenging times became one of the strategies to endure hardships. One participant described:

"Thank God (Alhamdulillah) that my husband still accepted me despite my condition now. I learned from other patients that their husbands mostly left them because of their condition to marry other women. Our neighbor was also the same. So, her husband had an affair. Alhamdulillah (thank God), I mean, it makes me feel grateful for what I have, my husband remains loyal to me. He did not leave me for another woman. He accepted my condition, and he always helped me to go through all this mess." (P18)

\section{Submission to the will of god}

The majority of the participants in this study had a positive attitude to mortality as a result of their 
religious beliefs. They described that they were not afraid of death. Submitting to the will of God is necessary to achieve emotional and physical wellbeing. In Indonesian culture, people believe that there are three keys to happiness: (1) prayer (berdoa), (2) being grateful (bersyukur), and (3) surrendering to God's will (berserah) [17]. The research data illustrated that the participants' spiritual and religious beliefs played a major role in shaping and guiding their decisions to seek treatment. Their conviction that their life is in the hands of God encouraged them to undergo heart surgery, despite their fears of the risk of cardiac surgery itself. One participant explained:

"I just surrender to God, what God wants from me, how He shapes my path. I just hope that since God has given me many children, I believe that He would give me life too, long life so that I would be able to look after my children until they reach adulthood until they are successful in life. That's my prayer all the time..." (P16)

The participant showed a sincere submission to God's will through her narrative that helped her worry less about her condition. She coped with her illness by recognizing that the illness was part of God's plan for her. Many participants expressed similar statements; they frequently stated: "I believe that Allah always has the best scenario for us." Participants' faith in destiny enabled them to maintain a sense of value despite their unfortunate situations. They came to terms with their illness situation and could accept living life with it. Each woman's journey from the initial response to this new phase was long and hard. To cope with this situation, most of the participants relied on their faith to get them through the hardships: "For me, my principle is, I have already done my best, I'll let Allah do the rest." The importance of spirituality most probably arose from their inability to control all the aspects of their lives. Regardless of their religious beliefs, 19 of the participants fell back on religious practices and spiritual beliefs to cope with their cardiac condition. One participant stated:

"Well, initially, it was hard for me. I kept asking Allah, is it true? I mean, this is heart surgery, you know. I was so worried and uncertain. Thus, I decided to ask for advice from 'Pak Kyai' (a Muslim leader, someone who possesses spiritual strength and wisdom). I went to see him. He told me that I should do the operation. He assured me that everything would be okay. Then, he advised me to perform istikhara prayer if I still had any doubt about the procedure (istikhara: Is a prayer recited by Muslims when in need of guidance on an issue in life). Indeed, I followed his suggestion. I performed istikhara prayer so that the procedure would not harm me... After istikhara, I felt like I got the answer, and I felt certain that I had to do the operation." (P19)

\section{Accepting fate: "If I couldn't do anything, I should just live with it"}

Sincere acceptance helped the women in this study deal with the misfortunes in their lives. One of the participants described her resigned acceptance of her challenging situation: "If I couldn't do anything, I should just live with it." Most of the participants agreed that God plays an active role in their health; however, they also believe that their conscious deliberation to act on their conditions would determine their illness outcomes. One participant described;

“...life and death are in God's hands. We're all going to die, today or tomorrow. I hope that if I take the surgery, I will be healthy again so that I can travel to Mecca to perform Hajj. That's my thought. Finally, I decided to do the surgery. I am so glad that it's over now, Alhamdulillah." (P21)

\section{Getting closer to god}

The cardiac event and cardiac surgery heightened the participants' awareness of their mortality. The participants described that they sustained the feeling of having been given a second chance. Of the 26 participants, 20 of them discussed new hopes and dreams for their futures, which they hoped to fulfill. Moreover, the participants' increased awareness of mortality caused them to focus on having an enhanced outlook on life, making healthy lifestyle changes, enhancing spirituality, and spending more time with their family. One of the Muslim participants noted:

"...I become a better person. What I mean by a better person is, I became more religious now, from my previous self that did not wear a hijab (hijab is the head covering that many Muslim women wear); now, I want to wear hijab consistently in the future." (P19)

Twelve of the participants in this study expressed their desire to get closer to God as they never knew how long they would live. They believed that their life in this world was only temporary, and eternal life was life after death. Therefore, despite their faith, the participants believed that they would be punished and rewarded after death for how they had lived their lives. Another participant echoed:

"Now we just realized, oh when I was seriously ill like this, I couldn't do anything like before. Thus, when we are healthy, we must be close to God. Be grateful. In the past, when I was still healthy, I was always busy at my work, I had no time to be grateful, I had no time to pray, to worship, or anything else. So now, when I am ill, I have plenty of free time, I feel like l've been forced to take a break from my routine and to worship God more." (P22) 


\section{Discussion}

This study's findings indicated that the participants' understanding of submission to God's will, the higher power, was transformed into strength to face uncertainties in life. The findings emphasized the idea that God helped the people who helped themselves. Therefore, participants believed that God had the power to control their illness outcomes, and they accepted their limitations as human beings. These findings resonated with assertions by Harandy et al., [18] who looked at the coping and healthy behaviors among Iranian Muslim breast cancer survivors. They found that the participants believed that their cancer was part of God's plan, and they had no power to change their destiny. However, this belief did not stop them from searching for medical treatment. Previous qualitative research among Punjabi Sikh participants in Canada also found that religious faith was crucial for the patients in making sense of their diagnosis [19] Aligned with the findings of the current study, the Punjabi Sikh participants also incorporated their religious beliefs in relation to the Sikh philosophy ("responsibility to one's self") to make appropriate lifestyle adjustments. However, in a qualitative study of ethnic minority participants' experiences in accessing a CR program in England, Chauhan et al., [20] found that participants commonly cited religious reasons and participants' fatalistic beliefs for their non-attendance in the program.

The study findings demonstrated that gratitude to God, even in such difficult times, along with the sincere acceptance of their condition, helped the women endure hardship and achieve emotional and psychological wellbeing. These findings are consistent with the previous study of men and women with heart failure in Iran [21]. The researchers reported that participants' faith in God reinforced their positive attitudes toward life, provided a source of comfort to cope with life-threatening heart problems, as well as preventing feelings of desperation. The participants described that they tried to improve their relationship with God by praying. They believed that the illness came from God, so only God could give them the cure. There was a lot of evidence showing the importance of religious beliefs as the primary sources of coping for people with chronic disease.

The participants in this study described their illness as part of God's plan, aiming to test their strength. Although they believed that God had the power to control the outcomes of their illness, they also believed that their conscious deliberation to take measures to deal with their condition would determine their illness outcome. To accomplish this, they were taking an active role in seeking help. This behavior is in line with the results of a qualitative study among Javanese women with type II diabetes by Pitaloka and Hsieh [17]. The researchers reported that women believed that submission (pasrah) was the essential virtue the women needed to guide social interactions and maintain harmony [17]. In Javanese beliefs, submission to the will of God constitutes the highest stage of faith. The study revealed that submission did not necessarily connote a passive resignation to fate; recognizing their illness as part of God's will filled women with the strength to cope with their condition. In addition, the study also reported that women's understandings of their illness intertwined with their understanding of their faith.

Similarly, in a Kenya study conducted by Kimani et al. [22] found that most participants believed that God arranged their heart failure. They were resigned to their fate because they believed that their life and death were in God's hands. Some participants, whose symptoms deteriorated despite treatment, expressed feelings of guilt as they felt they had wronged God so that now God did not help them in their time of need. Therefore, most of the participants who were of the Christian faith turned to the church to find solace. In contrast, in a UK study, people with heart failure experienced a decline in their spiritual well-being as their physical symptoms deteriorated; many patients explicitly doubted the existence of life after death [23].

It is interesting to note that submission to God's will as described by the women in this study did not represent a resignation to fate, as is often portrayed in the concept of fatalism or inaction conceptualized in the West [24]. The existing literature suggested that fatalism encompassed a lack of internal control over external events [25], beliefs in the notion of fate, luck, destiny, and predestination [26], and feelings of powerlessness, hopelessness, and meaninglessness [27]. On the other hand, in the Javanese context, submission demonstrates a person's emotional and spiritual maturity [17, p.1162]. In this sense, submission requires an active and persistent approach from individuals to demonstrate their humility. Geertz (1960), in Pitaloka and Hsieh [17], stated that submission facilitated individuals to achieve emotional composure, which, in turn, empowered them to control their feelings. Handayani and Novianto [28] asserted that submission gave strength to the Javanese women so that they could endure suffering. Similar findings were reported by Galdas and Kang [19] in their study of Punjabi Sikh patients' experiences in a CR program. The findings showed that despite the fatalistic beliefs that the participants held, they made several dietary and exercise changes as part of the responsibility to themselves.

Religious beliefs took a prominent role in the study participants' illness experience, irrespective of their religions. Religious values had helped the women accept their new condition, trust their strength, and cope with heart disease and surgery. It echoed previous research, which suggested that religious beliefs helped individuals cope with their disease, find a sense of wellbeing, and help in the decision-making for their care and treatment [29]. It is also possible their belief would 
increase their emotional resilience [30], [31], [32]. Numerous studies reported the importance of religion and spirituality as patients' primary sources of the strength needed to cope with chronic and life-threatening diseases [33], [34], [35], [36].

The findings suggested that the participants in this study were affiliated with Islam and Christianity. Irrespective of their religious groups, the participants explained that spiritual and religious beliefs played an enormous role in making sense of their situation. The women's conviction that their lives were in God's hands helped them in retaining inner peace and encouraging them to follow the treatment regime. However, contrary to these findings, a study among underprivileged men in Canada following cardiac surgery reported that all participants expressed a lack of control over their illness outcomes, which led to the adoption of unhealthy behavior [37]. Many men in Savage's study stated that they could not control their health status due to their belief in fate and God's will; a perception which inclined them to adopt a passive approach. In addition, most of the participants were skeptical about their ability to modify their lifestyles, and so they could not see any benefits of their actions.

In Savage's study, participants' fatalistic beliefs were associated with a passive resignation to their fate [37], an attitude that contradicted the meaning of "submission" within the Javanese culture. Interestingly, in this Indonesian study, most participants agreed that God played an active role in their health; however, they also believed that their conscious deliberation to act on their conditions would determine their illnesses outcomes. This data indicated that participants' understanding of submission to the will of God was transformed into empowerment. They believed that God worked directly or indirectly with the medical team, making decisions for them. The participants believed that God had the power to control their illness outcomes, and they accepted and acknowledged their limitations as human beings. However, their beliefs did not necessarily lead to powerlessness or hopelessness; instead, their faith helped them adjust to their illness and encouraged them to seek treatment.

The participants' description of getting closer to God was manifested by praying and worshiping God more than they had done in the past. The recent cardiac incidents had made the women aware that death was close, and their life in this world was only temporary. The women explained that they wanted to be more serious in preparing for their eternal life after death, rather than just pursuing worldly pleasures. The manifestation of heart disease had changed the women's perspectives on life. This sensitization is similar to the findings of a study conducted by Shahrbabaki et al., [21] which reported that the patients with heart failure in Iran also experienced mental growth and development following their illness. Suffering from the disease had increased their tolerance against problems, changed their perspectives on life, and considered the disease as a base for peace after death (Shahrbabaki et al., 2017).

This study, however, has several limitations. First, since this study was only carried out in one hospital in Indonesia, this study's findings might not reflect a larger Indonesian perspective. The generalization, therefore, must be made very cautiously. Second, all the women who participated in this study had undergone cardiac surgery. Hence, their experiences might differ from those whose heart disease was medically managed.

\section{Conclusion}

The findings showed that spiritual and religious beliefs played an enormous role in the participants' illness experience, irrespective of their religions. Religious values have helped the women to accept their new condition, trust their strength, and cope with heart disease and surgery. The women's conviction that their lives were in God's hands helped them in retaining inner peace and encouraging them to follow the treatment regime. Further study should be directed to explore the effect of cultural and spiritual values on women's recovery rates from heart disease. In addition, a comparative study of the experiences of women with heart disease in Western and Asian settings can be conducted.

\section{Acknowledgments}

We would like to thank all the women who participated in this study and shared their stories.

\section{References}

1. Emslie C. Women, men and coronary heart disease: A review of the qualitative literature. J Adv Nurs. 2005;51(4):382-95. https:// doi.org/10.1111/j.1365-2648.2005.03509.x PMid:16086807

2. World Health Organization. Non Communicable Diseases (NCD) Country Profiles. Geneva; World Health Organization: 2014.

3. Lockyer L, Bury M. The construction of a modern epidemic: The implications for women of the gendering of coronary heart disease. J Adv Nurs. 2002;39(5):432-40. https://doi. org/10.1046/j.1365-2648.2002.02308.x

4. World Health Organization. Global Health Observatory: Mortality and Global Health Estimates. Geneva: World Health Organization; 2015. 
5. Ministry of Health. Data dan Informasi Profil Kesehatan Indonesia 2017. Jakarta, Indonesia: Ministry of Health of the Republic Indonesia; 2018. https://doi.org/10.18311/jeoh/2020/26134

6. Lawton J. Lay experiences of health and illness: Past research and future agendas. Sociol Health IIIn. 2003;25:23-40. https:// doi.org/10.1111/1467-9566.00338

PMid: 14498928

7. Ida R. The construction of gender identity in Indonesia: Between cultural norms, economic implications, and state formation. Masyarakat Kebudayaan Politik. 2001;14(1):21-34.

8. Mulyani L. Women and Work in Indonesia. J Asian Ethn. 2009;10(2):187-91.

9. Sitepu HS. Queen of the household: An empty title. In: OeyGardiner M, Bianpoen C, editors. Indonesian Women: The Journey Continues. Canberra, Australia: Research School of Pacifics and Aisan Studies, ANU; 2000. p. 189-202.

10. Gergen KJ. An Invitation to Social Construction. London: Sage Publications; 1999.

11. Gale NK, Heath G, Cameron E, Rashid S, Redwood S. Using the framework method for the analysis of qualitative data in multi-disciplinary health research. BMC Med Res Methodol. 2013;13(117):1-8. https://doi.org/10.1186/1471-2288-13-117 PMid:24047204

12. Ritchie J, Spencer L. Qualitative data analysis for applied policy research. In: Bryman A, Burgess G, editors. Analysing Qualitative Data. London: Routledge; 1994. p. 173-94. https:// doi.org/10.4324/9780203413081_chapter_9

13. Ritchie J, Lewis J, McNaughton Nicholls C, Ormston R. In: Ritchie J, Lewis J, McNaughton Nicholls C, Ormston R, editors. Qualitative Research Practice: A Guide for Social Science Students and Researchers. $2^{\text {nd }}$ ed. Los Angeles: Sage Publications; 2014.

14. Lincoln YS, Guba EG. Naturalistic Inquiry. Thousand Oaks: Sage Publications; 1985.

15. Seah AC, Tan KK, Huang Gan JC, Wang W. Experiences of patients living with heart failure: A descriptive qualitative study. J Transcult Nurs. 2016;27(4):392-9. https://doi. org/10.1177/1043659615573840

\section{PMid:25724928}

16. Najafi Ghezeljeh T, Yadavar Nikravesh M, Emami A. Coronary heart disease patients transitioning to a normal life: Perspectives and stages identified through a grounded theory approach. J Clin Nurs. 2014;23(3-4):571-85. https://doi.org/10.1111/jocn.12272 PMid:24175915

17. Pitaloka D, Hsieh E. Health as submission and social responsibilities: Embodied experiences of Javanese women with Type II diabetes. Qual Health Res. 2015;25(8):1155-65. https://doi.org/10.1177/1049732315577607

18. Harandy TF, Ghofranipour F, Montazeri A, Anoosheh M, Bazargan M, Mohammadi E, et al. Muslim breast cancer survivor spirituality: Coping strategy or health seeking behavior hindrance? Health Care Women Int. 2009;31(1):88-98. https:// doi.org/10.1080/07399330903104516 PMid:20390638

19. Galdas PM, Kang HB. Punjabi Sikh patients' cardiac rehabilitation experiences following myocardial infarction: A qualitative analysis. J Clin Nurs. 2010;19(21-22):3134-42. https://doi.org/10.1111/j.1365-2702.2010.03430.x PMid:21040018

20. Chauhan U, Baker D, Lester H, Edwards R. Exploring uptake of cardiac rehabilitation in a minority ethnic population in England: A qualitative study. Eur J Cardiovasc Nurs. 2010;9(1):68-74. https://doi.org/10.1016/j.ejcnurse.2009.10.003 PMid:19932059

21. Shahrbabaki PM, Nouhi E, Kazemi M, Ahmadi F. Spirituality: A panacea for patients coping with heart failure. Int J Community Based Nurs Midwifery. 2017;5(1):38-48.

22. Kimani KN, Murray SA, Grant L. Spiritual issues of people living and dying with advanced heart failure in Kenya: A qualitative serial interview study. BMJ Glob Health. 2016;1(3):e000077. https://doi.org/10.1136/bmjgh-2016-000077

23. Murray SA, Kendall M, Grant E, Boyd K, Barclay S, Sheikh A Patterns of social, psychological, and spiritual decline toward the end of life in lung cancer and heart failure. J Pain Symptom Manage. 2007;34(4):393-402. https://doi.org/10.1016/j. jpainsymman.2006.12.009

\section{PMid:17616334}

24. Franklin MD, Schlundt DG, McClellan LH, Kinebrew T, Sheats J, Belue R, et al. Religious fatalism and its association with health behaviors and outcomes. Am J Health Behav. 2007;31(6):56372. https://doi.org/10.5993/ajhb.31.6.1

PMid:17691869

25. Davison C, Frankel S, Smith GD. The limits of lifestyle: Re-assessing 'fatalism' in the popular culture of illness prevention. Soc Sci Med. 1992;34(6):675-85. https://doi. org/10.1016/0277-9536(92)90195-v

PMid: 1574735

26. Straughan PT, Seow A. Fatalism reconceptualized: A concept to predict health screening behavior. J Gender Cult Health. 1998;3(2):85-100.

27. Powe BD. Fatalism among elderly African Americans. Effects on colorectal cancer screening. Cancer Nurs. 1995;18(5):385-92. https://doi.org/10.1097/00002820-199510000-00008

28. Handayani CS, Novianto A. The Power of Javanese Women. Yogyakarta: LKiS; 2004.

29. Ebadi A, Ahmadi F, Ghanei M, Kazemnejad A. Spirituality: A key factor in coping among Iranians chronically affected by mustard gas in the disaster of war. Nurs Health Sci. 2009;11(4):344-50. https://doi.org/10.1111/j.1442-2018.2009.00498.x PMid:19909438

30. Sidhu MS, Griffith L, Jolly K, Gill P, Marshall T, Gale NK. Longterm conditions, self-management and systems of support: An exploration of health beliefs and practices within the Sikh community, Birmingham, UK. Ethn Health. 2016;21(5):498-514. https://doi.org/10.1080/13557858.2015.1126560 PMid:26758646

31. Nortvedt L, Kumar BN, Lohne V. A qualitative study of immigrant women on long-term sick leave and their experience of dignity. Disabil Rehabil. 2018;40(19):2242-9. https://doi.org/10.1080/09 638288.2017.1331379 PMid:28549409

32. Shanthakumari RS, Chandra PS, Riazantseva E, Stewart DE. 'Difficulties come to humans and not trees and they need to be faced': A study on resilience among Indian women experiencing intimate partner violence. Int J Soc Psychiatry. 2014;60(7):70310. https://doi.org/10.1177/0020764013513440 PMid:24351964

33. Bhattacharyya M, Stevenson F, Walters K. Exploration of the psychological impact and adaptation to cardiac events in South Asians in the UK: A qualitative study. BMJ Open. 2016;6(7):e010195. https://doi.org/10.1136/ bmjopen-2015-010195

PMid:27401355

34. Oh PJ, Kim SH. The effects of spiritual interventions in patients with cancer: A meta-analysis. Oncol Nurs Forum. 2014;41(5):E290-301. PMid:25158666

35. Rochmawati E, Wiechula R, Cameron K. Centrality of spirituality/ religion in the culture of palliative care service in Indonesia: An ethnographic study. Nurs Health Sci. 2018;20(2):231-7. https:// doi.org/10.1111/nhs.12407 


\section{PMid:29336107}

36. Balboni TA, Paulk ME, Balboni MJ, Phelps AC, Loggers ET, Wright AA, et al. Provision of spiritual care to patients with advanced cancer: Associations with medical care and quality of life near death. J Clin Oncol. 2010;28(3):445-52. https://doi. org/10.1200/jco.2009.24.8005

\section{PMid:20008625}

37. Savage M, Dumas A, Stuart SA. Fatalism and short-termism as cultural barriers to cardiac rehabilitation among underprivileged men. Sociol Health IIIn. 2013;35(8):1211-26. https://doi. org/10.1111/1467-9566.12040

PMid:24266752 